Article

\title{
Exploring the Potential Distribution of Relic Trochodendron aralioides: An Approach Using Open-Access Resources and Free Software
}

\author{
Ching-An Chiu ${ }^{1}\left(\mathbb{D}\right.$, Tetsuya Matsui ${ }^{2,3}$ (D) Nobuyuki Tanaka ${ }^{4,+}$ and Cheng-Tao Lin ${ }^{5, *(\mathbb{C})}$ \\ 1 Experimental Forest, National Chung Hsing University, Taichung 402202, Taiwan; cachiu@nchu.edu.tw \\ 2 Center for Biodiversity and Climate Change, Forestry and Forest Products Research Institute, \\ Forest Research and Management Organization, Tsukuba 305-8687, Japan; tematsui@affrc.go.jp \\ 3 Faculty of Life and Environmental Sciences, University of Tsukuba, Tsukuba 305-8577, Japan \\ 4 Department of International Agricultural Development, Tokyo University of Agriculture, \\ Tokyo 156-8502, Japan; ntanaka1298@gmail.com \\ 5 Department of Biological Resources, National Chiayi University, Chiayi 600355, Taiwan \\ * Correspondence: mutolisp@mail.ncyu.edu.tw; Tel.: +886-5-2717829 \\ + Current office: Environment Consultant ENVI, Tsukuba 305-0062, Japan.
}

Citation: Chiu, C.-A.; Matsui, T.;

Tanaka, N.; Lin, C.-T. Exploring the Potential Distribution of Relic Trochodendron aralioides: An Approach Using Open-Access Resources and Free Software. Forests 2021, 12, 1749. https://doi.org/10.3390/f12121749

Academic Editor: Steven McNulty

Received: 18 October 2021

Accepted: 9 December 2021

Published: 11 December 2021

Publisher's Note: MDPI stays neutral with regard to jurisdictional claims in published maps and institutional affiliations.

Copyright: (C) 2021 by the authors Licensee MDPI, Basel, Switzerland. This article is an open access article distributed under the terms and conditions of the Creative Commons Attribution (CC BY) license (https:/ / creativecommons.org/licenses/by/ $4.0 /)$.

\begin{abstract}
Trochodendron aralioides Siebold \& Zucc. is a relic tree that is discontinuously scattered across the mountainous areas of Japan, Taiwan, and South Korea, but the origin of T. aralioides in South Korea is still unclear and debated. To confirm its distribution and explore its origins, we constructed a streamlined framework to examine potential species distribution using multiple open access data and free and open-source software, as well as employing maximum entropy principles to predict the potential distribution of $T$. aralioides. The results showed reasonably good discrimination and were used to examine and discuss the explicit distribution of T. aralioides. The potential distribution of T. aralioides in Japan extended from Iriomote Island to approximately $37^{\circ} \mathrm{N}$ in Honshu on the Pacific Ocean side. In Taiwan, the potential distribution of T. aralioides was more common than in Japan. It occurred at 1500-3000 m a.s.l. across the Central Mountain Range and decreased toward the northern and southern tips, correlating to the descending pattern of the cloud belt. Thermal and moisture conditions were important factors to determine the distribution of T. aralioides. The potential distribution indicated that Jeju island had high potential as a habitat for T. aralioides, and that may indirectly imply its existence and origins in South Korea, as some researchers have noted.
\end{abstract}

Keywords: Trochodendron aralioides; species distribution modeling; open-access resources; free software; MaxEnt

\section{Introduction}

Trochodendron aralioides Siebold and Zuccarini (Trochodendraceae Prantl) is a distinctive broad-leaved tree without a vessel in the woody tissue and is the only living species of this genus [1,2]. Although Trochodendron was widely distributed in the Northern Hemisphere during the geological ages in the past [3-6], the distribution of relic T. aralioides is currently restricted to East Asia [2]. In general, T. aralioides is distributed in the prevalent cloud zones of temperate or subtropical mountains in East Asia, but only a few distribution maps of T. aralioides were found in the Angiosperm Phylogeny website (http: / / www.mobot.org/MOBOT/research/APweb/; accessed on 19 September 2021) and GBIF georeferenced data map (http:/ / www.gbif.org/species/4191567; accessed on 19 September 2021). The spatially explicit distribution of T. aralioides still remains to be further explored.

Whether T. aralioides is a native species in South Korea is not clear due to the inconsistent descriptions of its natural distribution in different sources. It has been consistently described as a native species in Taiwan and Japan. In Taiwan, T. aralioides is moderately 
common in the prevalent cloud forests of the Central Mountain Ranges at 2000-3000 m above sea level (a.s.1.) and, in the northern part at 500-1050 m a.s.l., sometimes forms pure stands [7]. In the range of 2000-3000 $\mathrm{m}$ a.s.1. in Taiwan, the zonal vegetation comprises mixed needle-broad-leaved forests, in which the T. aralioides and Chamaecyparis species are significantly important, which indicates the significance of the humid environment [8]. In Japan, T. aralioides was found in the temperate zone [9], including in the Ryukyu Islands $[10,11]$. Interestingly, some literature has described the natural distribution of T. aralioides only in Taiwan and Japan $[2,7,12,13]$, but others have included South Korea $[6,10,11,14-17]$. However, this question may be addressed through species distribution modeling (SDM) based on niche theory and can explain the discontinuous distribution of T. aralioides.

Recently, SDM has proven useful in the fields of ecology and biogeography for theoretical and applied purposes [18-21]. Theoretically, SDM is based on the ecological niche theory, and it combines statistical or machine learning techniques and geographical information technology to simulate the species-environment relationship. Therefore, SDM is a progressively important tool in the prediction of the spatial distribution of a species [19,22], and it can be applied in the field of biological conservation $[19,23,24]$. Many articles concerning and utilizing SDM have emerged during the past two decades. For example, typing "species distribution model" in the search box of Thomson Reuters' Institute for Scientific Information (ISI) reveals only 439 related articles during 1991-2010, but there were 6766 related articles from January 2011 to June 2021. However, SDM studies were heavily relied on for geographical information science (e.g., [25-27]), and thus these geographical information system (GIS) tools to process SDM datasets are necessary for researchers.

In the past two decades, the "free software" movement initialized a novel way of considering information technologies, especially those used in scientific research, and it suggested a more cost-effective method for the future of scientific research, rather than continuing to rely on proprietary third-party software. In this paper, "free" does not mean "free of charge", but rather it refers to "freedom". There are four essential freedoms involved in "free software": (1) the freedom to use the software; (2) the freedom to study how it works and modify it to meet the needs of the user, which also means that it is open-source; (3) the freedom to redistribute the original software; and (4) the freedom to redistribute any user-modified source code (Free Software Foundation, https: / /www.fsf.org; accessed on 19 September 2021). Furthermore, the free software movement also helped to pave the way for data sharing, such as the recent open-data idea. For GIS tools, there are several free, modern GIS desktop software, such as GRASS (Geographic Resources Analysis Support System) GIS (http:/ / grass.osgeo.org; version 7.2.3) and QGIS (https:/ / qgis.org; version 3.2). Unlike the ArcMap and ArcDesktop series, most of the free GIS software are platform independent, i.e., usable on either a Windows, GNU/Linux, MacOS, or even BSD operating system. There are also several online open databases for biodiversity and ecological research, such as global biodiversity information facility (GBIF, URL: http:/ / gbif.org; accessed on 19 September 2021), WorldClim climate database (URL: https:/ / worldclim.org; accessed on 19 September 2021) [28] and free high-resolution global climate database CHELSA (URL: https: / / chelsa-climate.org; accessed on 19 September 2021) [29]. Access to these freely available online resources has made scientific research easier to complete [30-33]. Moreover, the prevalence of smart phones has engaged citizen scientists in data collection via crowd-sourcing using platforms, such as iNaturalist [34], which employs a "research grade" to lower the risk of errors (e.g., non-captive/cultivated species with more than two user-community identifications with two-thirds of the community members in concordance); the platform's aggregated data automatically export and integrate into the GBIF databases. In this study, we addressed the following topic and hypotheses: (1) propose an approach of using open-access data and free software, as well as other free tools, to process GIS data for species distribution models, and (2) determine the spatial distribution patterns of T. aralioides in East Asia, and which important variables have determined its distribution. 


\section{Materials and Methods}

\subsection{Target Species}

Trochodendron aralioides Siebold \& Zucc. (Trochodendraceae), more commonly referred to as an "evergreen" tree, is 5-25 $\mathrm{m}$ tall and glabrous with stout branches and terminal buds with paper-like scales. The leaves are crowded at the ends of the branches, almost whorled, 5-15 cm $\times 2-8 \mathrm{~cm}$, broadly ovate to lanceolate-elliptic or rarely elliptic, and are dark lustrous green adaxial surface with a pale abaxis. Flowers are bisexual, $1-2 \mathrm{~cm}$ in diameter, without petals, and with the radiative-spreading of 40-75 stamens surrounding the 5-11 carpels. They flower in March-June. The fruits mature in late August. More detailed descriptions have been reported by Watson and Dallwitz [35], Li and Chaw [7], Andrews [14], Fu and Endress [1], among others.

\subsection{Target Area}

Given that the natural distribution of T. aralioides has been restricted to East Asia, the study area ranged from $119^{\circ} \mathrm{E}$ to $146^{\circ} \mathrm{E}$ and $21^{\circ} \mathrm{N}$ to $46^{\circ} \mathrm{N}$. The modeling area covered all distributions denoted in the related literature (e.g., $[1,2,7,14])$, including Taiwan, Japan (excluding Hokkaido), and South Korea, but excluding China (see Figure 1 for occurrences and distribution area).

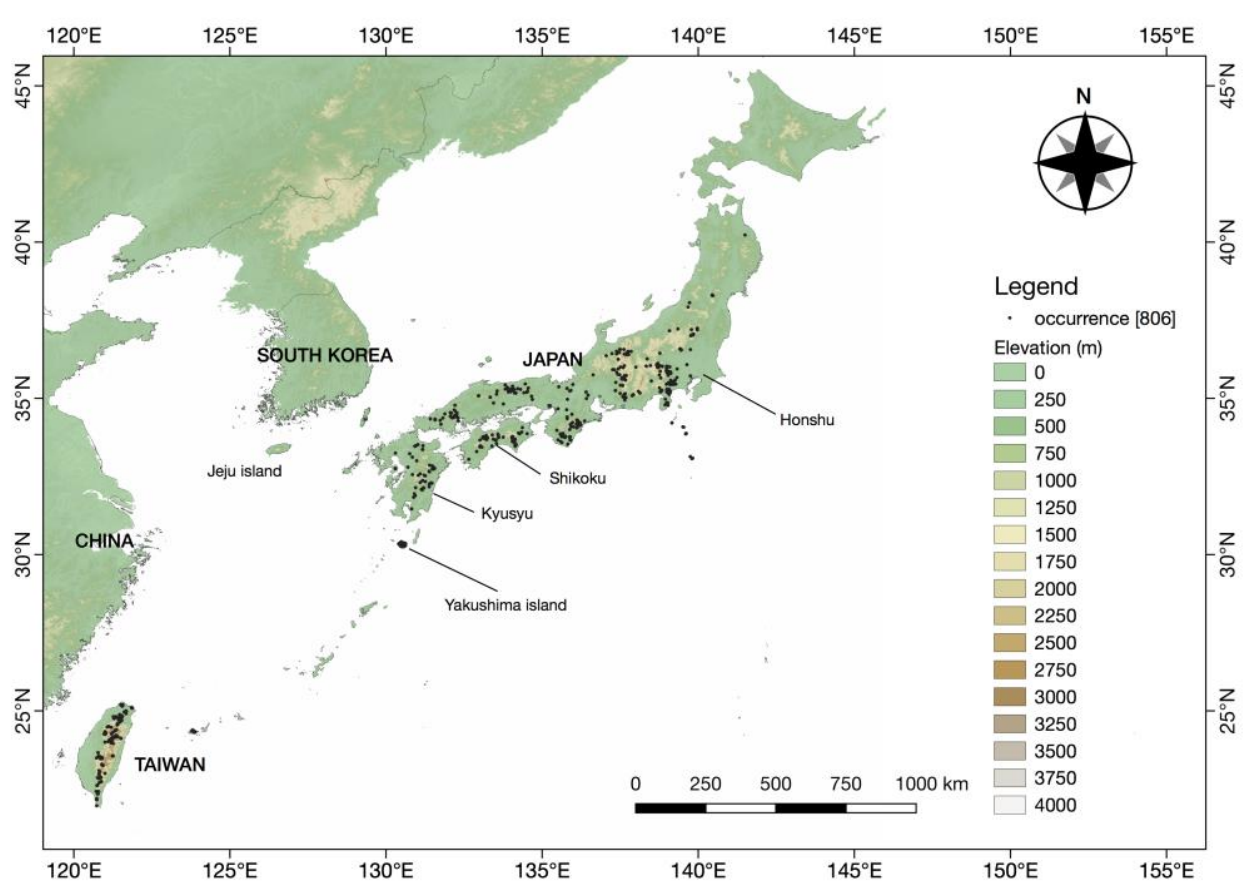

Figure 1. Study area and verified occurrences (806 points) of Trochodendron aralioides.

\subsection{Open-Access Resources and Free Software}

Many open-access resources can be accessed via the Internet, including geographical data and software. In this paper, we used the following five freely available online resources (Table 1) to model the distribution of T. aralioides. Figure 2 shows the flowchart of the integrated applications.

\subsubsection{Species Occurrences}

Since the number of occurrences in Japan was relatively small in the Global Biodiversity Information Facility (GBIF) database, we merged it with the occurrence data from the Phytosociological Relevé database (PRDB). PRDB is a phytosociological database composed of relevé data throughout Japan, while the original data sources were digitized from a variety of published and unpublished literature [36]. GBIF was established by recommendation from the Organization for Economic Cooperation and Development in 
2001 to encourage free and open access to biodiversity data. Through a global network of countries and organizations, GBIF promotes and facilitates the mobilization, access, discovery, and use of biodiversity information across spatial and temporal scales. Therefore, many researchers (e.g., Guralnick et al. [37]; Porretta et al. [38]) have used records sourced from GBIF search results to represent species occurrence samples, and many front-end interfaces have been developed with programming languages $\mathrm{R}$, Python, and Ruby to access GBIF occurrence data [39]. Since the data were collected by different methods and the data quality would be important for accurate modeling, we adopted the data-cleaning framework employed by Maletic and Marcus [40], which included three steps: (1) to define error types, (2) to identify error instances, and (3) to correct the defined errors. Chapman (2005) also introduced several data-cleaning principles for biodiversity spatial data, such as verifying georeferences against other information, and checking spatial accuracy against other information using GIS, etc. In this study, we defined three error types: (1) occurrence data out of the target area, such as occurrences in the United Kingdom; (2) impossible locality, such as for occurrences in the Pacific Ocean; and (3) duplicate entries. We used QGIS to test for and remove the aforementioned errors to ensure the accuracy of the data used for modeling.

\subsubsection{Environmental Variables}

High-resolution climate data are essential for ecological studies at a global or regional scale, and interpolation methods are typically required with meteorological station data, such as PRISM, WorldClim [28], and CHELSA [29], etc. Many researchers have used WorldClim layers as environmental variables, such as Ashraf et al. [41], Meneguzzi et al. [42], Porto et al. [43], and Rupprecht et al. [44]. However, the CHELSA datasets integrate wind and topological factors to correct for bias, which is why they are considered more robust and accurate than WorldClim datasets [29]. CHELSA provides global climatic layers downscaled to 30 arcseconds $(\sim 1 \mathrm{~km})$, which are therefore more precise than the other free global climate databases, such as CliMond [45], for ecological modeling and geographic information system. The climate conditions data include monthly precipitation; mean, minimum, and maximum temperature, as well as altitude; and 19 bioclimatic layers; however, some of the environmental factors are estimated [44]. Therefore, the most common method of variable selection for SDM was based on pairwise Pearson correlation coefficients [46,47]. We excluded bioclimatic variables that had a correlation coefficient $>0.75$. However, the determining climatic variables of Trochodendron aralioides were still unclear, so we also used jackknife resampling analysis (a leave-one-out resampling technique to evaluate the environmental variables) to assess the most important variables for model building.

Table 1. Open-access resources used in this study for species distribution modeling.

\begin{tabular}{|c|c|c|c|}
\hline Data or Tool & URL $^{1}$ & Service & License/Access \\
\hline GBIF & https://www.gbif.org/ & $\begin{array}{l}\text { Supplying biodiversity data as } \\
\text { species dataset }\end{array}$ & $\mathrm{CC}^{2}, \mathrm{CC}$ BY or $\mathrm{CC} \mathrm{BY}-\mathrm{NC}$ \\
\hline iNaturalist $^{3}$ & https://inaturalist.org/ & Crowdsourcing biodiversity occurrences & CC BY, CC BY-NC \\
\hline WorldClim & https://www.worldclim.org/ & $\begin{array}{l}\text { Supplying high-resolution bioclimatic and } \\
\text { elevation layers as environment datasets }\end{array}$ & $\begin{array}{l}\text { Free download. No } \\
\text { distribution }\end{array}$ \\
\hline CHELSA & https://chelsa-climate.org & $\begin{array}{l}\text { Supplying high-resolution bioclimatic and } \\
\text { elevation lavers as environment datasets }\end{array}$ & CC BY 4.0 \\
\hline $\begin{array}{l}\text { GRASS GIS } \\
\text { QGIS }\end{array}$ & $\begin{array}{c}\text { https://grass.osgeo.org/ } \\
\text { https://qgis.org/ }\end{array}$ & $\begin{array}{l}\text { GIS data processing } \\
\text { GIS data processing }\end{array}$ & $\begin{array}{l}\text { General Public License (GPL) } \\
\text { GPL version } 2\end{array}$ \\
\hline PostGIS & https://postgis.net & $\begin{array}{l}\text { GIS data processing (integration } \\
\text { with QGIS) }\end{array}$ & GPL version 2 \\
\hline $\mathrm{R}$ & https://www.r-project.org & $\begin{array}{l}\text { Statistical computing and data } \\
\text { preprocess/postprocess }\end{array}$ & GPL version $2 / 3$ \\
\hline MaxEnt & $\begin{array}{l}\text { https://biodiversityinformatics. } \\
\text { amnh.org/open_source/maxent/ }\end{array}$ & $\begin{array}{l}\text { modeling the species distribution through } \\
\text { species-environment relationships }\end{array}$ & MIT License \\
\hline
\end{tabular}

\footnotetext{
${ }^{1}$ Accessed on 19 September 2021. ${ }^{2}$ CC $=$ Creative Commons License; CC0 = public domain; CC BY = CC attribution; NC = non-commercial.
}

${ }^{3}$ The "research grade" observations periodically exported to GBIF. 


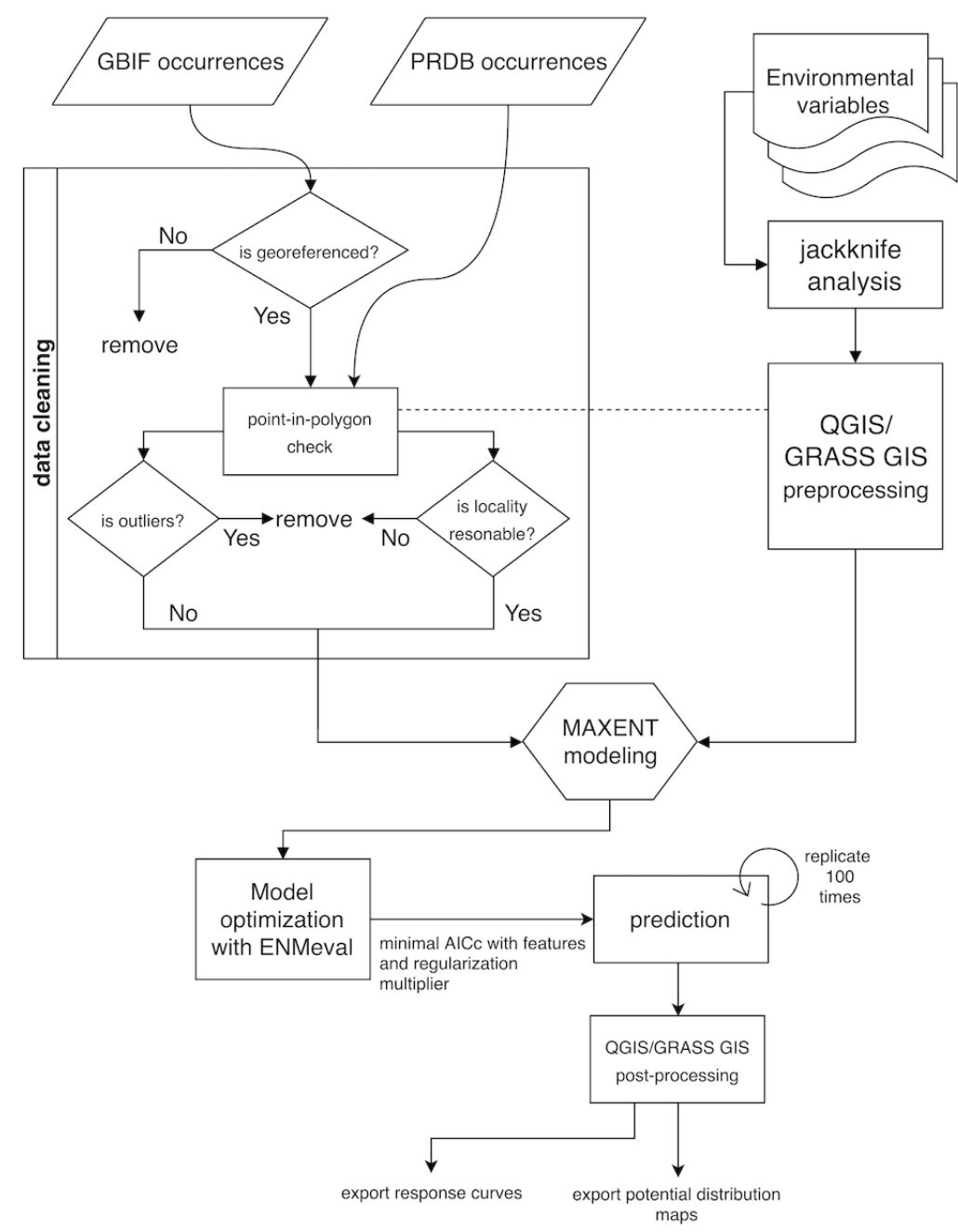

Figure 2. Flowchart of modeling species distribution through an integrated application of openaccess resources.

\subsubsection{GIS: GRASS GIS and QGIS}

GRASS GIS is a free GIS software used for geospatial data management and analyses, image processing, cartographic production, spatial modeling, and visualization. GRASS has been developing for more than 34 years, and it includes many geographical algorithms that have been used regularly for environmental modeling [48]. QGIS is also a free GIS desktop software; in addition to its tools for vector and raster processing, the most advanced feature is that it can function as a wrapper of third-party GISs (e.g., call the function or programs of GRASS GIS, Saga GIS, PostgreSQL/PostGIS or even R programs while working inside QGIS). In this study, we used QGIS as the main GIS processing tool and called GRASS functions by a GRASS plugin.

\subsubsection{MaxEnt}

MaxEnt is a machine-learning method based on maximum entropy principles, and its presence-only method is suitable for species investigation datasets [49]. Although there are many SDM techniques [19,20,50], MaxEnt was selected to model the potential distribution of $T$. aralioides for the following two reasons. First, the accuracy associated with occurrences has been a common concern when using location data [51,52]. The spatial positions of T. aralioides in GBIF have often been in error. MaxEnt is more robust than other methods, especially in regression-based modeling, in spatial errors of species occurrence [53]. Second, the sample size (occurrence records) of T. aralioides is relatively small in the scale of East Asia. MaxEnt has performed better than other methods with small sample sizes [44,54,55]. 


\subsection{Model Building and Validation}

We developed the SDMs with MaxEnt, version 3.4.1, using nine important environmental variables and cleaned data. Before predicting our model, we used the ENMeval package of $R$ to evaluate and test a range of parameters to optimize MaxEnt's model parameters [56,57]. We randomly created 10,000 background points and applied a checkboard2 algorithm to create spatial blocks in order to avoid model-overfitting issues in MaxEnt. A set of features including linear $(\mathrm{L})$, quadratic $(\mathrm{Q})$, product $(\mathrm{P})$, threshold $(\mathrm{T})$, and hinge $(\mathrm{H})$ as well as regularization multipliers (RMs) from 0.25 to 1.5 with 0.25 intervals were tested in the ENMevaluate function and to calculate the corrected Akaike information criterion (AICc) and determine an optimized model. Furthermore, in order to achieve statistical significance, we also executed 100 replications with 5000 iterations per replication in MaxEnt to obtain the mean probability of the potential distribution map.

We used the area under the receiver operating characteristics curve (AUC); a thresholdindependent method that characterizes the performance of a model at all possible thresholds by a single number to evaluate the modeling performance [49]. The modeling performance was categorized into three classes, as described by Swets [58]: poor discrimination $(0.5<$ AUC $<0.7)$, reasonable discrimination $(0.7<$ AUC $<0.9)$, and very good discrimination $(0.9<$ AUC $<1.0)$. However, several studies reported that the AUC would not be a good measure of performance in SDMs [59,60], so we also used the AICc from the ENMeval package to increase the discrimination of the model.

\section{Results}

\subsection{Species Dataset}

The numbers of T. aralioides records contained in the PRDB and GBIF database obtained in July 2018 were 529 and 1729, respectively (Table S1 from Supplementary Materials). Among them, only 943 records had been georeferenced. We excluded 214 occurrences based on a point-in-polygon check (i.e., joining attributes by location in QGIS) and data-cleaning procedures (e.g., remove duplicates, doubtful records, etc.) available in the QGIS and PostgreSQL databases. Besides the outliers of occurrences, there were several plots located in residential areas, such as in a garden or a park. Therefore, we had 806 occurrence records of $T$. aralioides with verified coordinates as the species dataset, with 308 records in Taiwan, 498 records in Japan, and none in South Korea (see Figure 1). The species-occurrence samples were exported from the PostgreSQL database via a comma-separated-values (.csv) file, which served as the input data for MaxEnt. The 806 samples were located within an area of occurrence spread across 683 modeling environmental grids (with a resolution of 30 arcseconds) due to the occurrence of several records in the same grid. Table 2 presents the statistical summary of the bioclimatic layers in our modeling area and in the occurrence grids.

\subsection{MaxEnt Modeling and Performance}

The ENMevaluate results revealed that the lowest AICc $(18,897.19)$ was the combination of LQ and LQPT features with an RM $=0.25$ (Figure S1). The average tested AUC was 0.8821, and the trained AUC was 0.8873 . The distribution modeling by MaxEnt for T. aralioides obtained reasonable discrimination with an AUC mean value of 0.8577 (0.6738-0.9733) for the training data and $0.8588(0.8555-0.8619)$ for the testing data. The modeling distribution map of T. aralioides is shown in Figure 3. The highest probabilities of predicting hot spots were in the Central Mountain Range in Taiwan (including the low elevation areas of the northern and southern tips that include winter northeast monsoon-facing slopes); the mountainous ranges of Honshu, Shikoku, Kyushu, Yakushima Island, and Iriomote Island in Japan; and Jeju Island in South Korea. Figure S2 shows the results of the jackknife test and the training gains for evaluating the relative contributions of the predictor environmental variables for the MaxEnt T. aralioides model. The estimates of the relative contributions of five environmental variables are given in Table S2. Based on the permutation importance, the most important variables were BIO5, BIO12, and BIO1, explaining 36.4, 30.8, and 12.7 
of variation in the distribution of T. aralioides, respectively. The aforementioned three variables contributed to almost $80 \%$ of our model; the other variables had relatively low contributions in terms of permutation importance. The response curves, shown in Figure 4, further detailed how each of the environmental variables altered the model prediction.

Table 2. Statistical summary of environmental variables for modeling area and for all grids of T. aralioides occurrences.

\begin{tabular}{ccccc}
\hline & \multicolumn{2}{c}{ Modeling Area } & \multicolumn{2}{c}{ Occurrence Grids } \\
\hline Environmental Variable & Mean & SD & Mean & SD \\
\hline BIO1 (annual mean temperature) * & 13.5 & 3.5 & 13.1 & 3.4 \\
BIO2 (mean diurnal range) * & 5.9 & 1.5 & 5.0 & 1.6 \\
BIO3 (isothermality) * & 20.7 & 3.7 & 22.8 & 6.2 \\
BIO4 (temperature seasonality) & 774.3 & 133.32 & 593.5 & 182.0 \\
BIO5 (max temperature of warmest month) * & 27.5 & 2.56 & 24.0 & 3.5 \\
BIO6 (min temperature of coldest month) & -0.6 & 5.3 & 1.8 & 5.4 \\
BIO7 (temperature annual range) & 28.1 & 4.7 & 22.2 & 6.2 \\
BIO8 (mean temperature of wettest quarter) ${ }^{*}$ & 21.6 & 5.4 & 19.2 & 3.3 \\
BIO9 (mean temperature of driest quarter) & 5.1 & 6.0 & 6.6 & 5.4 \\
BIO10 (mean temperature of warmest quarter) & 24.4 & 2.7 & 21.3 & 3.6 \\
BIO11 (mean temperature of coldest quarter) & 2.9 & 4.9 & 5.0 & 4.8 \\
BIO12 (annual precipitation) & 1724 & 542.8 & 2684.2 & 940.4 \\
BIO13 (precipitation of wettest month) & 281.3 & 99.4 & 426.4 & 170.9 \\
BIO14 (precipitation of driest month) & 60.1 & 35.0 & 97.4 & 65.1 \\
BIO15 (precipitation of seasonality) & 51.4 & 21.0 & 48.7 & 17.6 \\
BIO16 (precipitation of wettest quarter) & 786.7 & 270.0 & 1180.7 & 449.6 \\
BIO17 (precipitation of driest quarter) & 192.5 & 107.7 & 312.1 & 203.8 \\
BIO18 (precipitation of warmest quarter) * & 667.5 & 230.1 & 937.4 & 342.8 \\
BIO19 (precipitation of coldest quarter) * & 232.8 & 153.4 & 364.7 & 233.9 \\
\hline
\end{tabular}

* denotes the selected variables for modeling T. aralioides distribution in MaxEnt.

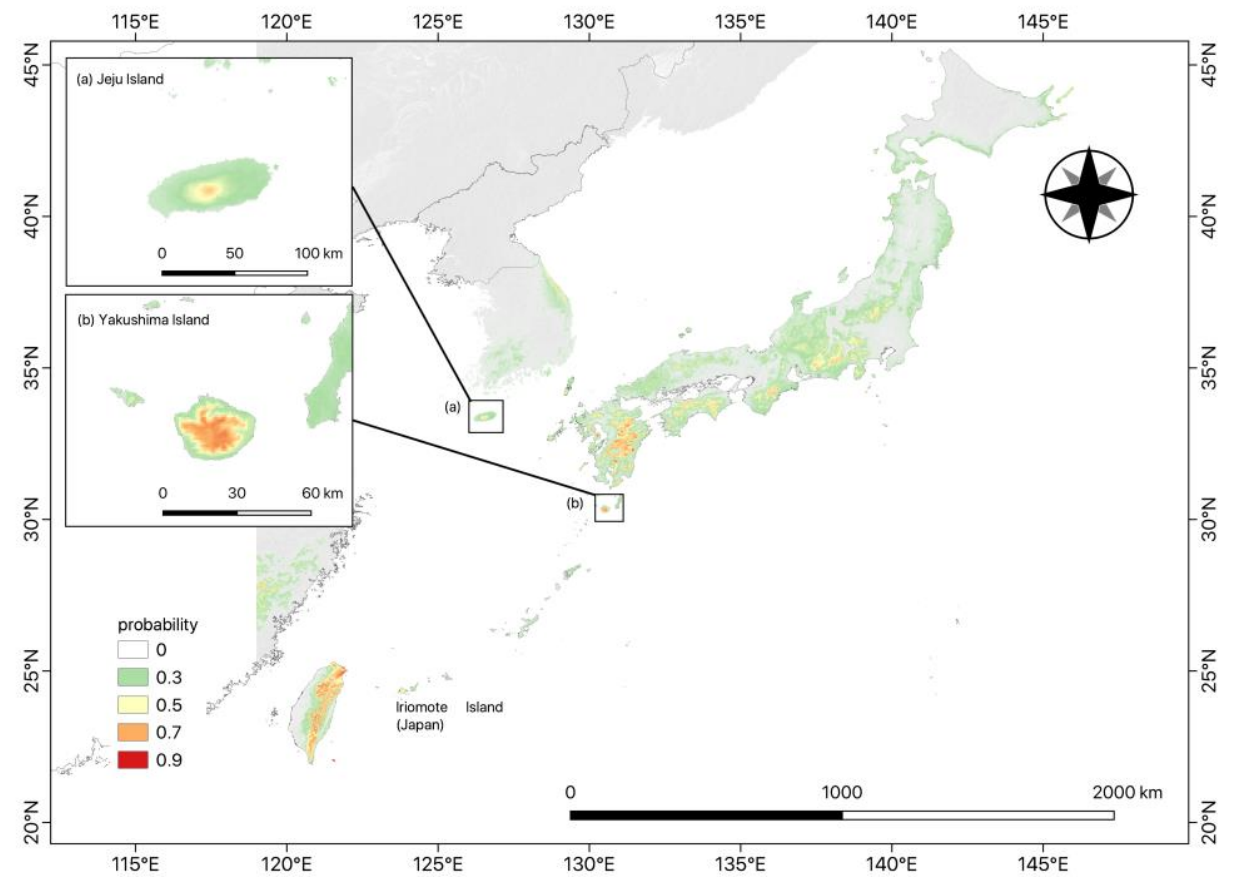

Figure 3. The potential distribution map of Trochodendron aralioides modeled by MaxEnt. (a) An enlarged map of Jeju Island in South Korea and (b) the enlarged map of Yakushima Island in Japan. 
(a)

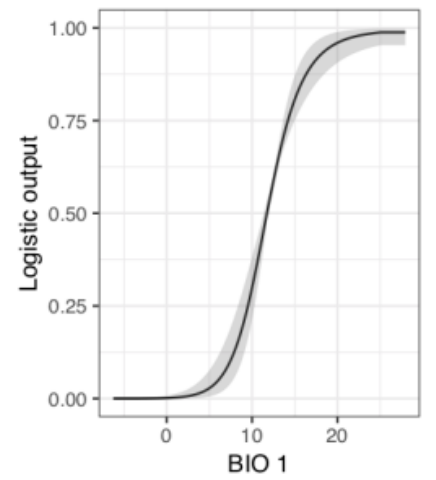

(d)

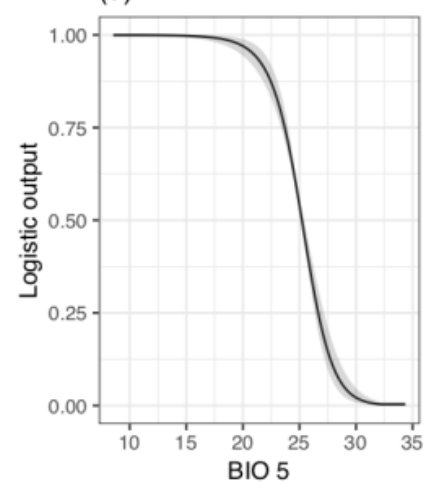

(g)

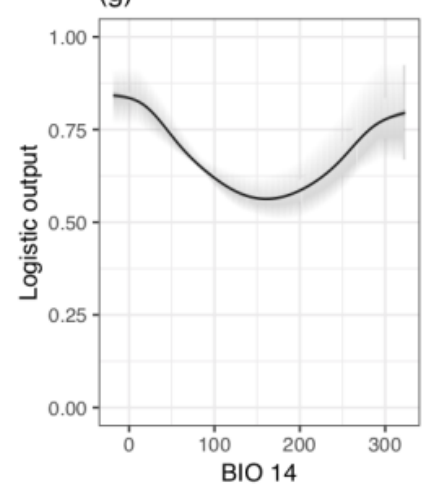

(b)

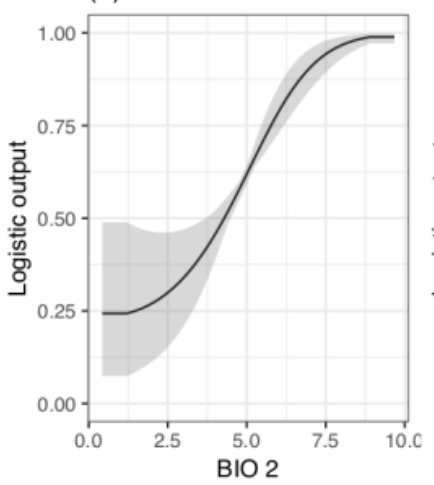

(e)

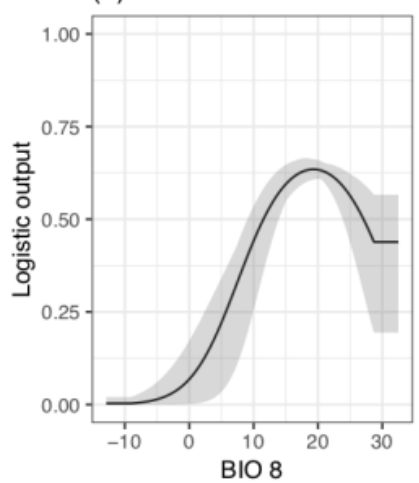

(h)

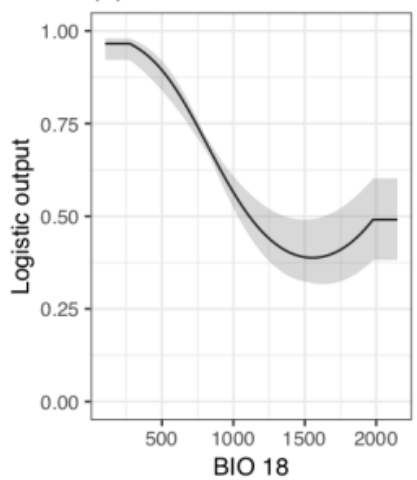

(c)

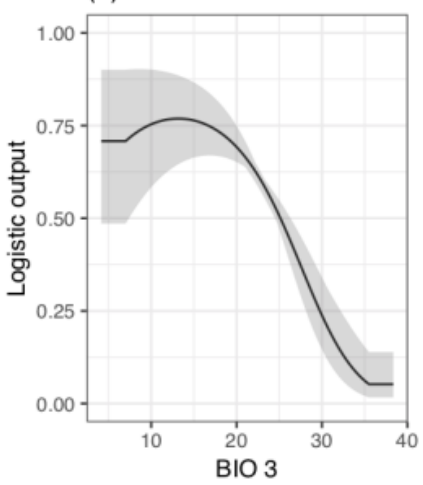

(f)

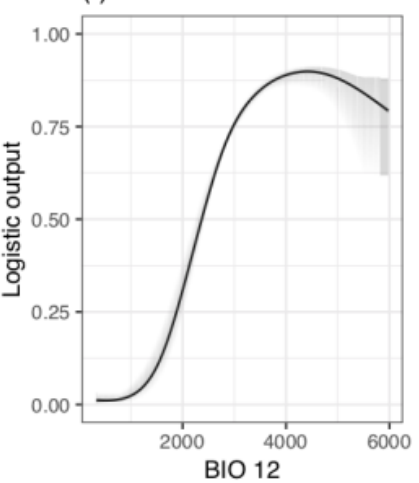

(i)

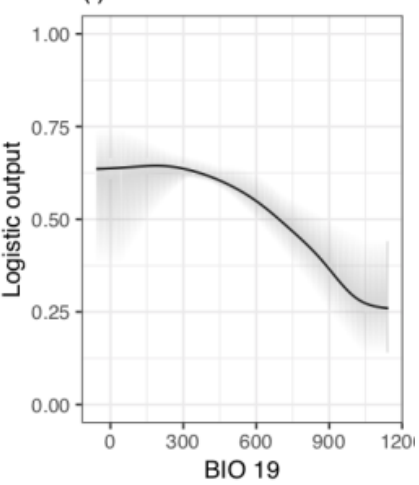

Figure 4. The response curves of logistic prediction changes of the environmental variables. The black curve represents the average of 100 replicates while the gray background indicates the range of values: (a-e) $x$-axis unit, ${ }^{\circ} \mathrm{C}$ and $(\mathbf{f}-\mathbf{i}) x$-axis unit, $\mathrm{mm}$.

\section{Discussion}

\subsection{Data Quality for Species Occurrence}

GBIF was the largest single source of global biodiversity occurrence data. In this study, there were 1729 records of T. aralioides accessed from GBIF's online database, but $786(\sim 45 \%)$ records did not have georeferenced information. Most of these non-georeferenced records were obtained from herbariums and museums prior to the invention of global positioning systems and would likely have temporal sampling biases [61,62]. Comparatively, the PRDB data had better quality overall, as compared to the GBIF data (e.g., only 10 occurrences showed georeferenced errors, $\sim 2 \%$ ), particularly since most of the occurrence records were based on a phytosociological survey and were digitized from herbarium specimens with low geographical resolution. Furthermore, among the 943 GBIF records with georeferenced information, $444(47 \%)$ records did not pass geographic validation tests or were determined to be duplicates through the data cleaning process in QGIS (Table S1). This determination 
was made based on conditions noted by Yesson et al. [63], including undersea coordinates and georeferenced errors, as well as conditions considered in this study, including coordinates located in distinctly residential areas and improbable altitudes (e.g., ranging 300-3000 $\mathrm{m}$ a.s.l. in Taiwan) $[1,7,64]$. The spatial bias of the species records had been widely discussed regarding both theoretical errors and real cases [63,65-69]. Filtering out these biases in occurrence records would be a pioneering achievement as the bias data heavily influences the accuracy and reliability of the SDMs [70-72]. Of the 308 acceptable records in Taiwan, $217(70.5 \%)$ were from vegetation diversity inventories and mapping plans (Chiou et al. [73]; also see Table S1, GBIF dataset key: 9edd4990-4138-11de-b28fb8a03c50a862). Therefore, integrating vegetation inventory databases, such as the Global Index of Vegetation-Plot Databases (http:/ / www.givd.info; accessed on 19 September 2021) with the 313 databases and 3,630,327 plots registered (date accessed: October 2021), into the GBIF database was a critical factor for broadening and refining biodiversity occurrence data $[74,75]$.

\subsection{Distribution of T. aralioides}

\subsubsection{Japan}

As shown in Figure 3, T. aralioides was distributed across the mountains of Honshu, Shikoku, and Kyushu. The northeast occurrence of T. aralioides was on the Iwate Prefecture, but there was only one point that would need further validation. However, the probable northern limit of T. aralioides was near Yamagata City, Yamagata Prefecture, such as in Mount Funagata and Mount Zao, at approximately $38^{\circ} \mathrm{N}$ as denoted by Wu et al. [13]. Around $35^{\circ} \mathrm{N}$, T. aralioides occurred on the piedmont slopes of Mount Fuji and the southern parts of the Akaishi and Kiso Mountains, but not on the alpine slopes where coniferous trees were dominant. In addition to the mainland of Japan, T. aralioides also occurred on the Izu [76] and Ryukyu Islands [6,7,10,14-16]. On Yakushima Island $\left(30.2^{\circ} \mathrm{N}, 130.3^{\circ} \mathrm{E}\right.$, Figure $3 b$ ), which is one UNESCO's World Heritage Sites largely due to its unique vegetation, T. aralioides was a frequent feature in forest vegetation at 500-1800 $\mathrm{m}$ a.s.l., along with Cryptomeria japonica D.Don and Tsuga sieboldii Carrière [77-82].

Our results indicated that temperature-related variables, such as BIO5, were very important based on our models, and BIO5 was a limiting factor for the lower or southern distribution of $T$. aralioides. The potential distribution map (Figure 3) also showed the same pattern, while highly potential habitats were located on the Pacific side of the Honshu region. Figure $4 \mathrm{~d}$ shows the probability of T. aralioides abruptly decreasing under BIO5 $>23{ }^{\circ} \mathrm{C}$ conditions. However, the precipitation-related variables, such as BIO12 (annual precipitation) also played important roles in the distribution of T. aralioides (see Figure $4 \mathrm{f}$ ), but they required further research that was outside the scope of this study. Comparing the altitudinal ranges of T. aralioides in Japan and Taiwan (Huang et al. [83]; also see Table S1), T. aralioides in Japan (at high latitudes) occurred at lower altitudes than those in Taiwan (at low latitudes). Therefore, the thermal conditions were critical factors in T. aralioides distribution.

\subsubsection{Taiwan}

In contrast with the potential T. aralioides distribution in Japan, the distribution was relatively wide in Taiwan. It was moderately common in the mid-altitude forests of the Central Mountain Range [7], in the 1500-3000 m a.s.l. regions. Wu et al. [13] noted that central Taiwan was a probable refuge for T. aralioides during the last glacial periods due to those populations having the greatest genetic diversity. The altitudinal range of T. aralioides decreased considerably to the north and south $[8,13,64,83,84]$. As shown in Figure 3, the lowest altitude of $T$. aralioides distribution was at approximately $400 \mathrm{~m}$ a.s.l. in the northern region, then gradually increased up to $1300 \mathrm{~m}$ a.s.l. in the central region, and then finally descended to $500 \mathrm{~m}$ a.s.l. in the southern region. The altitudinal pattern of $T$. aralioides has been correlated with the position of cloud belts [8]. T. aralioides favor cool, humid habitats. In Japan, for example, T. aralioides tended to occur in steep slopes and 
sometimes near bodies of water in the mountains, whereas in Taiwan, it had extended widely across the mountainous regions, where cloud belts are known to form. T. aralioides has been considered as an indicator for prevalent cloud zones where Quercus oak trees may also be found [8]. Within the cloud belt of the Central Mountain Range, T. aralioides is typically mixed with coniferous trees (e.g., Chamaecyparis formosensis Matsum. and Cunninghamia konishii Hayata) and other broad-leaved trees (e.g., Quercus morii Hayata and Neolistea spp.; [8]). In the northern and southern regions of Taiwan, T. aralioides occurred in areas coinciding with cloud belts, but where coniferous trees were absent, suggesting that both were subject to thermal conditions. In this study, we used the novel effective warmth index (EWI), which associates the temperature sum with the thermal seasonality [85], to describe the T. aralioides habitat and applied the equal training sensitivity and specificity logistic threshold test [86] to classify our model predictions into suitable and unsuitable habitats. As shown in Figure 5, EWI = 160 isoline (yellow line) approximately matched the lowest limit of $T$. aralioides highly suitable habitat in the Central Mountain Range. Consequently, the distribution of T. aralioides was related to thermal variables and seasonal precipitation rather than to a simple climate factor.

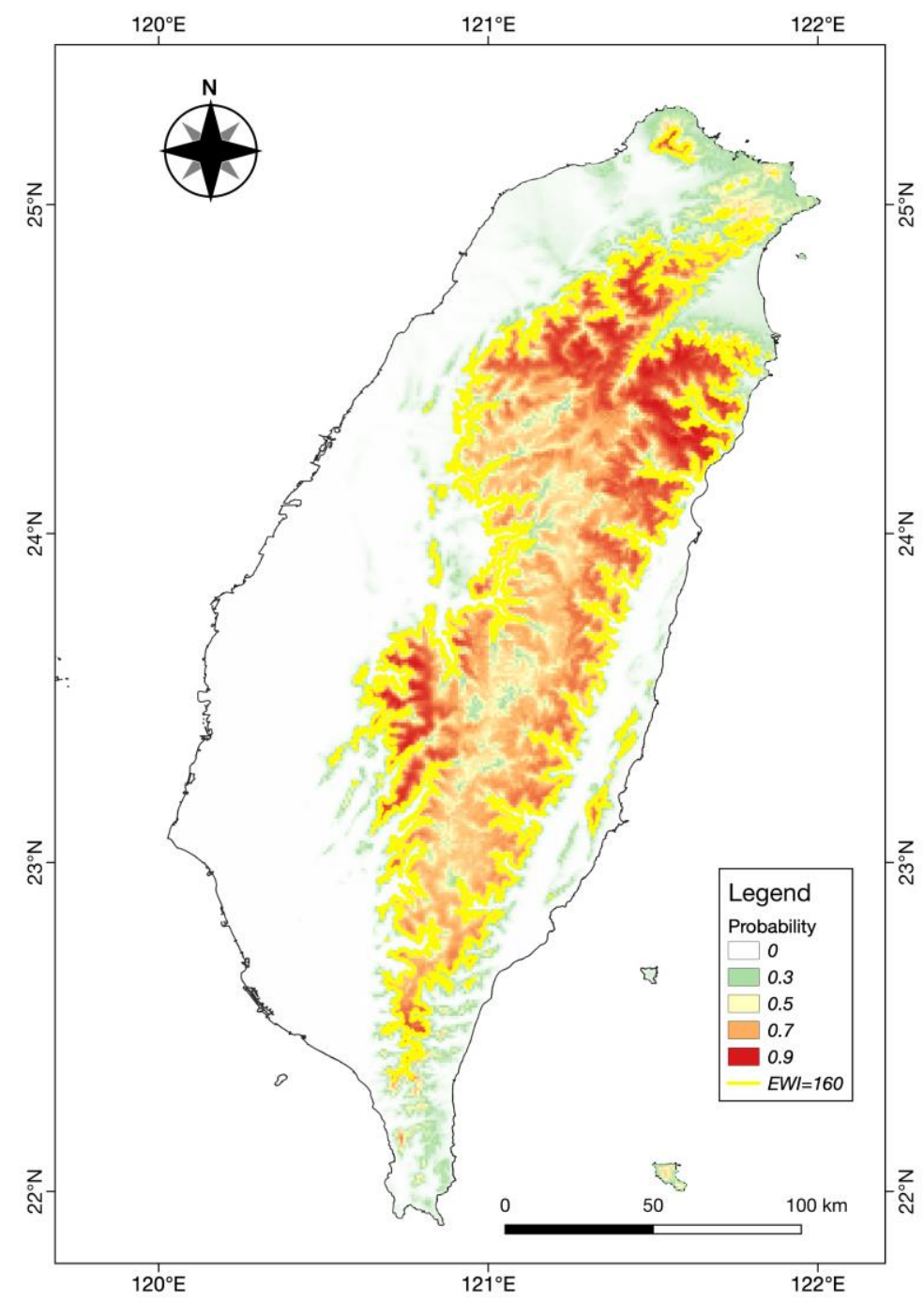

Figure 5. The overlap map of the T. aralioides habitat and the effective warmth index (EWI, EWI $=100$ : black dotted line; EWI $=40$ : black line) approximately matched the lowest and highest limit of T. aralioides potentially suitable habitats in the Central Mountain Range. Black dots are occurrences. 


\subsection{T. aralioides in South Korea?}

There were two opposing views regarding whether T. aralioides is native to South Korea or not. Most of the literature $[6,10,11,15,16,87]$ has noted that the natural distribution of T. aralioides includes Taiwan, Japan, and South Korea. However, Wu et al. [13] and Andrews [14] opposed this point of view, as did Korean scientist Koh [88], all of whom agreed that Trochodendron aralioides did not originate on the Korean peninsula and its adjacent islands, though many foreign publications have suggested that this species could be found in the southern part of Korea. Furthermore, the flora identified in the Hallasan Natural Reserve in Jeju island did not include T. aralioides [89]. However, our results (Figure 3a) showed that Jeju Island in South Korea had a high probability (around 0.7-0.8) of T. aralioides. Nonetheless, whether T. aralioides is native to South Korea could not be determined and will require additional research.

On one hand, T. aralioides may not be native in South Korea. Our SDM was based on the concept of the realized niche [90] despite the arguments of Pearson and Dawson [91], as well as Soberón [92]. The probability of occurrence did not represent the real occurrence because the actual range was part of the potential range [93,94]. However, our SDM did not consider the potential effects of biotic exclusion, historical contingency, dispersal limitations, land usage, or species ranges that restrict the geographic expression of the fundamental niche $[95,96]$. Thus, Jeju Island may be a suitable habitat for T. aralioides; even so, T. aralioides may never have spread to there. On the other hand, T. aralioides may be native in South Korea. Brown et al. [97] noted that species tended to prosper in the center of their distribution and become rarer and more restricted to specific habitats towards the distribution margins. Our results indicated Jeju Island was a potential habitat of T. aralioides, but the presence of T. aralioides on the island has never been verified. However, an undiscovered or unrecorded species cannot prove a negative, i.e., that $T$. aralioides has never existed on Jeju Island. To answer the question about T. aralioides' native origins in South Korea, we could perhaps examine the surveys of Jeju island, especially the natural vegetation in Hallasan National Park. The discovery of a new species requires effort (e.g., vegetation surveys, specimen collections, time, etc.) and, in many cases, fortunate circumstances. In addition, it is possible that T. aralioides found refuge in central Taiwan during the last glacier period [13] and has not yet migrated to and settled in South Korea. Since one of the largest GBIF species occurrence datasets can be found in iNaturalist research-grade data, future research should consider further investigation concerning the origins and spread of T. aralioides in South Korea, namely on Jeju Island.

\section{Conclusions}

Trochodendron aralioides is an important indicator of prevalent cloud zones in Taiwan as well as Chamaecyparis species, whose disjointed distribution also reflects the historical impacts of prior climate changes. This study constructed a streamlined framework to predict the potential distribution of $T$. aralioides by applying species distribution modeling with multiple free software and open data sources. Our results showed that the most important environmental variables that influence the distribution of $T$. aralioides were BIO5 (maximum temperature of the warmest month), BIO12 (annual precipitation), and BIO1 (annual mean temperature), which implied that the maximum temperature of the warmest month would be the limitation factor and may be vulnerable to climate changes. In general, the distribution of T. aralioides in Japan was not common, except in the mountainous area of Yakushima Island. It was, however, common in the cloud zones in Taiwan. Therefore, conservation strategies can be developed based on the potential distribution probabilities of different countries. Regarding the uncertainty about the origins of T. aralioides in South Korea, we suggest that future research should consider examining Jeju island further, based on the results of our SDM, and develop a complete distribution map according to free, expansive data sources, such as iNaturalist. 
Supplementary Materials: The following are available online at https://www.mdpi.com/article/10 .3390 /f12121749/s1, Table S1: The occurrence table of Trochodendron aralioides, Table S2: Average relative contribution and permutation importance of the environmental variables of the MaxEnt model, Figure S1: Delta AICc of regularization multipliers for optimization of models, Figure S2: Results of jackknife analyses of regularized training gain (a) and test gain (b) for Trochodendron aralioides.

Author Contributions: Conceptualization, C.-T.L. and C.-A.C.; methodology, C.-T.L. and C.-A.C.; software, C.-T.L.; validation, C.-T.L., C.-A.C. and N.T.; formal analysis, C.-A.C. and C.-T.L.; resources, N.T. and T.M.; data curation, C.-T.L.; writing-original draft preparation, C.-T.L.; writing-review and editing, C.-T.L., C.-A.C., N.T. and T.M.; visualization, C.-T.L.; funding acquisition, T.M. and N.T. All authors have read and agreed to the published version of the manuscript.

Funding: This research was funded by the Taiwan Forestry Research Institute: The Project of Future Green, grant number: 110A008-01, the Japan Society for the Promotion of Science (JSPS), KAKENHI project, grant number: JP20H04380 and the Environment Research and Technology Development Fund of the Environmental Restoration and Conservation Agency of Japan, grant number: JPMEERF20202002.

Institutional Review Board Statement: Not applicable.

Informed Consent Statement: Not applicable.

Data Availability Statement: The GBIF occurrence data can be retrieved at https:/ / doi.org/10.154 68/dl.rqiwer [98]. The Phytosociological Relevé Data Base (PRDB) is available at: http:/ /www.ffpri. affrc.go.jp/labs/prdb/EnglishVer/index-e.html.

Conflicts of Interest: The authors declare no conflict of interest. The funders had no role in the design of the study; in the collection, analyses, or interpretation of data; in the writing of the manuscript, or in the decision to publish the results.

\section{References}

1. Fu, D.; Endress, P. Trochodendraceae. In Flora of China; Wu, Z., Ed.; Science Press: Beijing, China; St. Louis, MI, USA, 2001; Volume 6, p. 124.

2. Stevens, P.F.; Angiosperm Phylogeny Website. Version 12. Available online: http://www.mobot.org/MOBOT/research/APweb/ (accessed on 19 September 2021).

3. Lu, A.-M.; Li, J.-Q.; Chen, Z.-D. The origin and dispersal of the "lower" Hamamelidae. J. Syst. Evol. 1993, 31, 489-504.

4. Manchester, S.R.; Crane, P.R.; Dilcher, D.L. Nordenskioldia and Trochodendron (Trochodendraceae) from the Miocene of Northwestern North America. Bot. Gaz. 1991, 152, 357-368. [CrossRef]

5. Pigg, K.B.; Wehr, W.C.; Ickert-Bond, S.M. Trochodendron and Nordenskioldia (Trochodendraceae) from the Middle Eocene of Washington State, U.S.A. Int. J. Plant Sci. 2001, 162, 1187-1198. [CrossRef]

6. Pigg, K.B.; Dillhoff, R.M.; DeVore, M.L.; Wehr, W.C. New diversity among the Trochodendraceae from the early/middle Eocene Okanogan Highlands of British Columbia, Canada, and northeastern Washington State, United States. Int. J. Plant Sci. 2007, 168, 521-532. [CrossRef]

7. Li, H.; Chaw, S. Trochodendraceae. In Flora of Taiwan; Editorial Committee of Flora of Taiwan, Ed.; National Taiwan University: Taipei, Taiwan, 1996; Volume 2, pp. 504-505.

8. Su, H.-J. Studies on the climate and vegetation types of the natural forest in Taiwan. (II). Altitudinal vegetation zones in relation to temperature gradient. QJ Chin. For. 1984, 17, 57-73.

9. Yahara, T. Phytogeographical problems in the temperate flora in Japan. Current aspect of biogeography in west Pacific and East Asian regions. In Current Aspects of Biogeography in West Pacific and East Asian Regions; Oba, H., Hayami, I., Mochizuki, K., Eds.; University Museum, University of Tokyo, Nature and Culture: Tokyo, Japan, 1989; pp. 99-114.

10. Cronquist, A. An Integrated System of Classification of Flowering Plants; Columbia University Press: New York, NY, USA, 1981; ISBN 9780231038805.

11. Mabberley, D.J. The Plant-Book: A Portable Dictionary of the Higher Plants; Cambridge University Press: Cambridge, UK, 1997; ISBN 0524414210.

12. Hatushima, S. Flora of the Ryukyus: (Including Amami Islands, Okinawa Islands, and Sakishima Archipelago); Okinawa Society of Biological Education and Research: Okinawa, Japan, 1971. (In Japanese)

13. Wu, J.-E.; Huang, S.; Wang, J.-C.; Tong, W.-F. Allozyme variation and the genetic structure of populations of Trochodendron aralioides, a monotypic and narrow geographic genus. J. Plant Res. 2001, 114, 45-57. [CrossRef]

14. Andrews, S. Tree of the Year: Trochodendron aralioides; International Dendrology Society: Herefordshire, UK, 2009 ; p. 48.

15. Wu, H.; Su, H.; Hu, J. The identification of A-, B-, C-, and E-Class MADS-box genes and implications for perianth evolution in the basal eudicot Trochodendron aralioides (Trochodendraceae). Int. J. Plant Sci. 2007, 168, 775-799. [CrossRef] 
16. Yang, X.; Lu, S.; Peng, H. Cytological studies on the eastern Asian family Trochodendraceae. Bot. J. Linn. Soc. 2008, 158, $332-335$. [CrossRef]

17. Ohwi, J. Trochodendraceae. In Flora of Japan; Meyer, F., Walker, E., Eds.; Smithsonian Institution: Washington, DC, USA, 1965; p. 438.

18. Austin, M.P. Spatial prediction of species distribution: An interface between ecological theory and statistical modelling. Ecol. Model. 2002, 157, 101-118. [CrossRef]

19. Elith, J.; Leathwick, J.R. Species distribution models: Ecological explanation and prediction across space and time. Annu. Rev. Ecol. Evol. Syst. 2009, 40, 677-697. [CrossRef]

20. Guisan, A.; Thuiller, W. Predicting species distribution: Offering more than simple habitat models. Ecol. Lett. 2005, 8, 993-1009. [CrossRef]

21. Guisan, A.; Zimmermann, N.E. Predictive habitat distribution models in ecology. Ecol. Model. 2000, 135, 147-186. [CrossRef]

22. Rodríguez-Castañeda, G.; Hof, A.R.; Jansson, R.; Harding, L.E. Predicting the fate of biodiversity using species' distribution models: Enhancing model comparability and repeatability. PLoS ONE 2012, 7, e44402. [CrossRef] [PubMed]

23. Sinclair, S.; White, M.; Newell, G. How useful are species distribution models for managing biodiversity under future climates? Ecol. Soc. 2010, 15, 8. [CrossRef]

24. Whitehead, A.L.; Kujala, H.; Ives, C.D.; Gordon, A.; Lentini, P.E.; Wintle, B.A.; Nicholson, E.; Raymond, C.M. Integrating biological and social values when prioritizing places for biodiversity conservation. Conserv. Biol. 2014, 28, 992-1003. [CrossRef] [PubMed]

25. Corsi, F.; Leeuw, J.; de Skidmore, A. Modeling species distribution with GIS. In Research Techniques in Animal Ecology; Boitani, L., Fuller, T., Eds.; Columbia University Press: New York, NY, USA, 2000; pp. 389-434.

26. Gogol-Prokurat, M. Predicting habitat suitability for rare plants at local spatial scales using a species distribution model. Ecol. Appl. 2011, 21, 33-47. [CrossRef]

27. Pandit, S.N.; Hayward, A.; Leeuw, J.; de Kolasa, J. Does plot size affect the performance of GIS-based species distribution models? J. Geogr. Syst. 2010, 12, 389-407. [CrossRef]

28. Fick, S.E.; Hijmans, R.J. WorldClim 2: New 1-km spatial resolution climate surfaces for global land areas. Int. J. Climatol. 2017, 37, 4302-4315. [CrossRef]

29. Karger, D.N.; Conrad, O.; Böhner, J.; Kawohl, T.; Kreft, H.; Soria-Auza, R.W.; Zimmermann, N.E.; Linder, H.P.; Kessler, M. Climatologies at high resolution for the earth's land surface areas. Sci. Data 2017, 4, 170122. [CrossRef]

30. Arzberger, P.; Schroeder, P.; Beaulieu, A.; Bowker, G.; Casey, K.; Laaksonen, L.; Moorman, D.; Uhlir, P.; Wouters, P. Promoting access to public research data for scientific, economic, and social development. Data Sci. J. 2004, 3, 135-152. [CrossRef]

31. Miller, R.H.; Masuoka, P.; Klein, T.A.; Kim, H.-C.; Somer, T.; Grieco, J. Ecological niche modeling to estimate the distribution of Japanese Encephalitis virus in Asia. PLoS Neglect. Trop. Dis. 2012, 6, e1678. [CrossRef] [PubMed]

32. Probert, R.J.; Daws, M.I.; Hay, F.R. Ecological correlates of ex situ seed longevity: A comparative study on 195 species. Ann. Bot. 2009, 104, 57-69. [CrossRef]

33. Tenopir, C.; Allard, S.; Douglass, K.; Aydinoglu, A.U.; Wu, L.; Read, E.; Manoff, M.; Frame, M. Data sharing by scientists: Practices and perceptions. PLoS ONE 2011, 6, e21101. [CrossRef] [PubMed]

34. Seltzer, C. Making biodiversity data social, shareable, and scalable: Reflections on iNaturalist \& citizen science. Biodivers. Inf. Sci. Stand. 2019, 3, e46670. [CrossRef]

35. Watson, L.; Dallwitz, M.J. The Families of Flowering Plants: Descriptions, Illustrations, Identification, and Information Retrieval. Available online: http:/ / delta-intkey.com/angio (accessed on 25 June 2017).

36. Tanaka, N. PRDB (Phytosociological Relevé Data Base). Available online: http:/ /www.ffpri.affrc.go.jp/labs/prdb/EnglishVer/ index-e.html (accessed on 23 July 2018).

37. Guralnick, R.P.; Hill, A.W.; Lane, M. Towards a collaborative, global infrastructure for biodiversity assessment. Ecol. Lett. 2007, 10, 663-672. [CrossRef] [PubMed]

38. Porretta, D.; Mastrantonio, V.; Bellini, R.; Somboon, P.; Urbanelli, S. Glacial history of a modern invader: Phylogeography and species distribution modelling of the Asian tiger mosquito Aedes albopictus. PLoS ONE 2012, 7, e44515. [CrossRef]

39. Chamberlain, S.A.; Boettiger, C. R Python, and Ruby clients for GBIF species occurrence data. PeerJ Prepr. 2017, 5, e3304v1. [CrossRef]

40. Maletic, J.; Marcus, A. Data cleansing: Beyond integrity analysis. In Proceedings of the 2000 Conference on Information Quality, Cambridge, MA, USA, 25-28 October 2000.

41. Ashraf, U.; Ali, H.; Chaudry, M.N.; Ashraf, I.; Batool, A.; Saqib, Z. Predicting the potential distribution of Olea ferruginea in Pakistan incorporating climate change by using Maxent model. Sustainability 2016, 8, 722. [CrossRef]

42. Meneguzzi, V.C.; Dos Santos, C.B.; Leite, G.R.; Fux, B.; Falqueto, A. Niche modelling of Phlebotomine sand flies and Cutaneous leishmaniasis identifies Lutzomyia intermedia as the main vector species in southeastern Brazil. PLoS ONE 2016, 11, e0164580. [CrossRef]

43. Porto, T.J.; Carnaval, A.C.; Rocha, P.L.B. da Evaluating forest refugial models using species distribution models, model filling and inclusion: A case study with 14 Brazilian species. Divers. Distrib. 2013, 19, 330-340. [CrossRef]

44. Rupprecht, F.; Oldeland, J.; Finckh, M. Modelling potential distribution of the threatened tree species Juniperus oxycedrus: How to evaluate the predictions of different modelling approaches? J. Veg. Sci. 2011, 22, 647-659. [CrossRef] 
45. Kriticos, D.J.; Webber, B.L.; Leriche, A.; Ota, N.; Macadam, I.; Bathols, J.; Scott, J.K. CliMond: Global high-resolution historical and future scenario climate surfaces for bioclimatic modelling. Methods Ecol. Evol. 2012, 3, 53-64. [CrossRef]

46. Parra, J.L.; Graham, C.C.; Freile, J.F. Evaluating alternative data sets for ecological niche models of birds in the Andes. Ecography 2004, 27, 350-360. [CrossRef]

47. Syfert, M.M.; Smith, M.J.; Coomes, D.A. The effects of sampling bias and model complexity on the predictive performance of maxent species distribution models. PLoS ONE 2013, 8, e55158. [CrossRef]

48. Neteler, M.; Bowman, M.H.; Landa, M.; Metz, M. GRASS GIS: A multi-purpose open source GIS. Environ. Model. Softw. 2012, 31, 124-130. [CrossRef]

49. Phillips, S.J.; Anderson, R.P.; Schapire, R.E. Maximum entropy modeling of species geographic distributions. Ecol. Model. 2006, 190, 231-259. [CrossRef]

50. Thuiller, W.; Lafourcade, B.; Engler, R.; Araújo, M.B. BIOMOD—A platform for ensemble forecasting of species distributions. Ecography 2009, 32, 369-373. [CrossRef]

51. Baldwin, R.A. Use of maximum entropy modeling in wildlife research. Entropy 2009, 11, 854-866. [CrossRef]

52. Moudrý, V.; Šímová, P. Influence of positional accuracy, sample size and scale on modelling species distributions: A review. Int. J. Geogr. Inf. Sci. 2012, 26, 2083-2095. [CrossRef]

53. Graham, C.H.; Elith, J.; Hijmans, R.J.; Guisan, A.; Peterson, A.T.; Loiselle, B.A.; The Nceas Predicting Species Distributions Working Group. The influence of spatial errors in species occurrence data used in distribution models. J. Appl. Ecol. 2008, 45, 239-247. [CrossRef]

54. Hernandez, P.A.; Graham, C.H.; Master, L.L.; Albert, D.L. The effect of sample size and species characteristics on performance of different species distribution modeling methods. Ecography 2006, 29, 773-785. [CrossRef]

55. Wisz, M.S.; Hijmans, R.J.; Li, J.; Peterson, A.T.; Graham, C.H.; Guisan, A.; Groupt, N.P.S.D.W. Effects of sample size on the performance of species distribution models. Divers. Distrib. 2008, 14, 763-773. [CrossRef]

56. Muscarella, R.; Galante, P.J.; Soley-Guardia, M.; Boria, R.A.; Kass, J.M.; Uriarte, M.; Anderson, R.P. ENMeval: An R package for conducting spatially independent evaluations and estimating optimal model complexity for Maxent ecological niche models. Methods Ecol. Evol. 2014, 5, 1198-1205. [CrossRef]

57. Warren, D.L.; Seifert, S.N. Ecological niche modeling in Maxent: The importance of model complexity and the performance of model selection criteria. Ecol. Appl. 2011, 21, 335-342. [CrossRef] [PubMed]

58. Swets, J.A. Measuring the accuracy of diagnostic systems. Science 1988, 240, 1285-1293. [CrossRef]

59. Lobo, J.M.; Jiménez-Valverde, A.; Real, R. AUC: A misleading measure of the performance of predictive distribution models. Glob. Ecol. Biogeogr. 2008, 17, 145-151. [CrossRef]

60. Fourcade, Y.; Besnard, A.G.; Secondi, J. Paintings predict the distribution of species, or the challenge of selecting environmental predictors and evaluation statistics. Glob. Ecol. Biogeogr. 2018, 27, 245-256. [CrossRef]

61. Daru, B.H.; Park, D.S.; Primack, R.B.; Willis, C.G.; Barrington, D.S.; Whitfeld, T.J.S.; Seidler, T.G.; Sweeney, P.W.; Foster, D.R.; Ellison, A.M.; et al. Widespread sampling biases in herbaria revealed from large-scale digitization. New Phytol. 2018, 217, 939-955. [CrossRef]

62. Meyer, C.; Weigelt, P.; Kreft, H. Multidimensional biases, gaps and uncertainties in global plant occurrence information. Ecol. Lett. 2016, 19, 992-1006. [CrossRef]

63. Yesson, C.; Brewer, P.W.; Sutton, T.; Caithness, N.; Pahwa, J.S.; Burgess, M.; Gray, W.A.; White, R.J.; Jones, A.C.; Bisby, F.A.; et al. How global Is the Global Biodiversity Information Facility? PLoS ONE 2007, 2, e1124. [CrossRef]

64. Chiu, C.A.; Chen, W.C.; Wang, C.C.; Chang, K.C.; Liao, M.C.; Hsu, H.S.; Tsai, C.Y. Is it true for "northern descent" phenomenon of Trochodendron aralioides spatial distribution. Q. J. For. Res. 2017, 39, 85-95.

65. Boakes, E.H.; McGowan, P.J.K.; Fuller, R.A.; Chang-qing, D.; Clark, N.E.; O'Connor, K.; Mace, G.M. Distorted Views of Biodiversity: Spatial and Temporal Bias in Species Occurrence Data. PLoS Biol. 2010, 8, e1000385. [CrossRef] [PubMed]

66. Garcia-Milagros, E.; Funk, V.A. Data: Improving the use of information from museum specimens: Using Google Earth@ to georeference Guiana Shield specimens in the US National Herbarium. Front. Biogeogr. 2012, 2, 71-77. [CrossRef]

67. Koenig, W.D.; Funk, K.A.; Kraft, T.S.; Carmen, W.J.; Barringer, B.C.; Knops, J.M.H. Stabilizing selection for within-season flowering phenology confirms pollen limitation in a wind-pollinated tree. J. Ecol. 2012, 100, 758-763. [CrossRef]

68. Graham, C.H.; Ferrier, S.; Huettman, F.; Moritz, C.; Peterson, A.T. New developments in museum-based informatics and applications in biodiversity analysis. Trends Ecol. Evol. 2004, 19, 497-503. [CrossRef]

69. Chapman, A.D. Principles of Data Quality; Global Biodiversity Information Facility: Copenhagen, Denmark, $2005 ;$ p. 58.

70. Bystriakova, N.; Peregrym, M.; Erkens, R.H.J.; Bezsmertna, O.; Schneider, H. Sampling bias in geographic and environmental space and its effect on the predictive power of species distribution models. Syst. Biodivers. 2012, 10, 305-315. [CrossRef]

71. Anderson, R.P. Harnessing the world's biodiversity data: Promise and peril in ecological niche modeling of species distributions Ann. N. Y. Acad. Sci. 2012, 1260, 66-80. [CrossRef]

72. Phillips, S.J.; Dudík, M.; Elith, J.; Graham, C.H.; Lehmann, A.; Leathwick, J.; Ferrier, S. Sample selection bias and presence-only distribution models: Implications for background and pseudo-absence data. Ecol. Appl. 2009, 19, 181-197. [CrossRef]

73. Chiou, C.-R.; Hsieh, C.-F.; Wang, J.-C.; Chen, M.-Y.; Liu, H.-Y.; Yeh, C.-L.; Yang, S.-Z.; Chen, T.-Y.; Hsia, Y.-J.; Song, G.-Z.M. The first national vegetation inventory in Taiwan. Taiwan J. For. Sci. 2009, 24, 295-302. 
74. Dengler, J.; Jansen, F.; Glöckler, F.; Peet, R.K.; Cáceres, M.D.; Chytrý, M.; Ewald, J.; Oldeland, J.; Lopez-Gonzalez, G.; Finckh, M.; et al. The Global Index of Vegetation-Plot Databases (GIVD): A new resource for vegetation science. J. Veg. Sci. 2011, 22, 582-597. [CrossRef]

75. Jansen, F.; Glöckler, F.; Chytrý, M.; Cáceres, M.D.; Ewald, J.; Finckh, M.; Lopez-Gonzalez, G.; Oldeland, J.; Peet, R.; Schaminée, J.; et al. News from the Global Index of Vegetation-Plot Databases (GIVD): The metadata platform, available data, and their properties. Biodivers. Ecol. 2012, 4, 77-82. [CrossRef]

76. Hoshino, Y.; Nozaki, R.; Isogai, T.; Maesako, Y.; Kamijo, T.; Kobayashi, H. Studies of Vegetation in Island Mikura-Jima Wilderness Area; The Nature Conservation Society of Japan: Tokyo, Japan, 1995; pp. 73-78. (In Japanese)

77. Ishii, H.; Takashima, A.; Makita, N.; Yoshida, S. Vertical stratification and effects of crown damage on maximum tree height in mixed conifer-broadleaf forests of Yakushima Island, southern Japan. Plant Ecol. 2010, 211, 27-36. [CrossRef]

78. Miyawaki, A. Vegetation of Japan; Gakken Education Publishing: Tokyo, Japan, 1977. (In Japanese)

79. Ohsawa, M. Latitudinal comparison of altitudinal changes in forest structure, leaf-type, and species richness in humid monsoon Asia. Vegetatio 1995, 121, 3-10. [CrossRef]

80. Suzuki, E.; Tsukahara, J. Age structure and regeneration of old growth Cryptomeria japonica forests on Yakushima Island. Bot. Mag. Shokubutsu-Gaku-Zasshi 1987, 100, 223-241. [CrossRef]

81. Yasuda, Y. Influences of the vast eruption of Kikai Caldera Volcano in the Holocene vegetational history of Yakushima, southern Kyushu, Japan. Jpn. Rev. 1991, 2, 145-160. (In Japanese) [CrossRef]

82. Yumoto, T. Pollination systems in the cool temperate mixed coniferous and broad-leaved forest zone of Yakushima Island. Ecol. Res. 1988, 3, 117-129. [CrossRef]

83. Huang, S.; Hwang, S.; Wang, J.; Lin, T. Phylogeography of Trochodendron aralioides (Trochodendraceae) in Taiwan and its adjacent areas. J. Biogeogr. 2004, 31, 1251-1259. [CrossRef]

84. Yeh, C. Study on the Vegetation Ecology of Lilung Mountain; Forest Bureau, Executive Yuan: Taipei, Taiwan, 2003; p. 100, (In Traditional Chinese).

85. Chiu, C.-A.; Lin, P.-H.; Hsu, C.-K.; Shen, Z.-H. A novel thermal index improves prediction of vegetation zones: Associating temperature sum with thermal seasonality. Ecol. Indic. 2012, 23, 668-674. [CrossRef]

86. Liu, C.; Berry, P.M.; Dawson, T.P.; Pearson, R.G. Selecting thresholds of occurrence in the prediction of species distributions. Ecography 2005, 28, 385-393. [CrossRef]

87. Manchester, S.R.; Chen, I. Tetracentron fruits from the Miocene of western North America. Int. J. Plant Sci. 2006, 167, 601-605. [CrossRef]

88. Koh, K.S. Some proposals on plant taxonomy of Korea. Korean J. Plant Taxono. 1980, 10, 7-11. [CrossRef]

89. Kim, C.-S.; Koh, J.-G.; Moon, M.-O.; Song, G.-P.; Hyun, H.-J.; Song, K.-M.; Kim, M.-H. Flora and life form spectrum of Hallasan Natural Reserve, Korea. J. Environ. Sci. Int. 2007, 16, 1257-1269. [CrossRef]

90. Pulliam, H.R. On the relationship between niche and distribution. Ecol. Lett. 2000, 3, 349-361. [CrossRef]

91. Pearson, R.G.; Dawson, T.P. Predicting the impacts of climate change on the distribution of species: Are bioclimate envelope models useful? Glob. Ecol. Biogeogr. 2003, 12, 361-371. [CrossRef]

92. Soberón, J. Grinnellian and Eltonian niches and geographic distributions of species. Ecol. Lett. 2007, 10, 1115-1123. [CrossRef]

93. Araújo, M.B.; Guisan, A. Five (or so) challenges for species distribution modelling. J. Biogeogr. 2006, 33, 1677-1688. [CrossRef]

94. Soberón, J.; Nakamura, M. Niches and distributional areas: Concepts, methods, and assumptions. Proc. Nat. Acad. Sci. USA 2009, 106, 19644-19650. [CrossRef]

95. Morin, X.; Thuiller, W. Comparing niche- and process-based models to reduce prediction uncertainty in species range shifts under climate change. Ecology 2009, 90, 1301-1313. [CrossRef]

96. Richards, C.L.; Carstens, B.C.; Knowles, L.L. Distribution modelling and statistical phylogeography: An integrative framework for generating and testing alternative biogeographical hypotheses. J. Biogeogr. 2007, 34, 1833-1845. [CrossRef]

97. Brown, J.H.; Mehlman, D.W.; Stevens, G.C. Spatial variation in abundance. Ecology 1995, 76, 2028-2043. [CrossRef]

98. GBIF.org. GBIF Occurrence of Trochodendron aralioides. Available online: https://doi.org/10.15468/dl.rqiwer (accessed on 26 July 2018). 